\title{
The impact of frailty on admission to home care services and nursing homes: eight- year follow-up of a community-dwelling, older adult, Spanish cohort
}

\author{
Francisco Cegri ${ }^{1,2}$, Francesc Orfila $^{2,3^{*}}$ (D), Rosa M. Abellana ${ }^{4}$ and María Pastor-Valero 5,6
}

\begin{abstract}
Background: Frailty in older adults is a common multidimensional clinical entity, a state of vulnerability to stressors that increases the risk of adverse outcomes such as functional decline, institutionalization or death. The aim of this study is to identify the factors that anticipate the future inclusion of community-dwelling individuals aged $\geq 70$ years in home care programmes $(\mathrm{HC})$ and nursing homes $(\mathrm{NH})$, and to develop the corresponding prediction models.

Methods: A prospective cohort study was conducted in 23 primary healthcare centers located in Catalonia, Spain, with an eight-year follow-up (2005-2013). The cohort was made up of 616 individuals. Data collection included a baseline multidimensional assessment carried out by primary health care professionals. Outcome variables were collected during follow-up by consulting electronic healthcare records, and the Central Registry of Catalonia for mortality. A prognostic index for a $\mathrm{HC}$ and $\mathrm{NH}$ at 8 years was estimated for each patient. Death prior to these events was considered a competing risk event, and Fine-Gray regression models were used.

Results: At baseline, mean age was 76.4 years and 55.5\% were women. During follow-up, $19.2 \%$ entered a HC program, $8.2 \%$ a NH , and $15.4 \%$ died without presenting an event. Of those who entered a $\mathrm{NH}, 31.5 \%$ had previously been in a $\mathrm{HC}$ program.

Multivariate models for a $\mathrm{HC}$ and $\mathrm{NH}$ showed that the risk of a $\mathrm{HC}$ entry was associated with older age, dependence on the Instrumental Activities of Daily Living, and slow gait measured by Timed-up-and-go test. An increased risk of being admitted to a NH was associated with older age, dependence on the Instrumental Activities of Daily Living, number of prescriptions, and the presence of social risk.

(Continued on next page)
\end{abstract}

\footnotetext{
* Correspondence: forfila.bcn.ics@gencat.cat

Unitat de Suport a la Recerca Barcelona, Fundació Institut Universitari per a la recerca a l'Atenció Primària de Salut Jordi Gol i Gurina (IDIAPJGol), IDIAP Jordi Gol. Gran Via Corts Catalanes 587, Àtic., 08007 Barcelona, Spain ${ }^{3}$ Gerència Territorial de Barcelona, Institut Català de la Salut, Barcelona, Spain Full list of author information is available at the end of the article
}

(c) The Author(s). 2020 Open Access This article is licensed under a Creative Commons Attribution 4.0 International License, which permits use, sharing, adaptation, distribution and reproduction in any medium or format, as long as you give appropriate credit to the original author(s) and the source, provide a link to the Creative Commons licence, and indicate if changes were made. The images or other third party material in this article are included in the article's Creative Commons licence, unless indicated otherwise in a credit line to the material. If material is not included in the article's Creative Commons licence and your intended use is not permitted by statutory regulation or exceeds the permitted use, you will need to obtain permission directly from the copyright holder. To view a copy of this licence, visit http://creativecommons.org/licenses/by/4.0/. The Creative Commons Public Domain Dedication waiver (http://creativecommons.org/publicdomain/zero/1.0/) applies to the data made available in this article, unless otherwise stated in a credit line to the data. 
(Continued from previous page)

Conclusions: Prognostic models based on comprehensive geriatric assessments can predict the need for the commencement of $\mathrm{HC}$ and $\mathrm{NH}$ admission in community-dwelling older adults. Our findings underline the necessity to measure functional capacity, mobility, number of prescriptions, and social aspects of older adults in primary healthcare centers. In such a setting they can be offered longitudinal holistic assessments so as to benefit from preventive actions in order to remain independent in the community for as long as possible.

Keywords: Cohort study, Frail elderly, Primary health care, Risk prediction models, Long-term home care, Long-term institutional care

\section{Background}

Worldwide, progressive population aging presents increasingly multiple health, social, and economic consequences for systems with inadequate planning and resources. This demographic change is leading to an augmented prevalence of chronic diseases and frailty in older adults, resulting in loss of autonomy and placing a heavier burden on health and social care [1-4].

In Spain, $17 \%$ of the inhabitants are currently > 65 years, and projections for 2050 indicate that the figure will reach 33\% compared to the expected 29\% in neighbouring European countries [4]. Many older individuals are, or will become, frail. Such a condition in the elderly is a multidimensional clinical entity that represents a state of vulnerability to stressors [5], including a reduction in physical, mental, and social functions, and predicts adverse events such as hospitalization [6], institutionalization [7], and death [8].

There are different ways to measure frailty, the most common measurements are the frailty phenotype [9] and the deficit accumulation model [10]. Other tools include performance tests (such as the Short Physical Performance Battery and the Timed-Up-and-go Test) and scales that assess the instrumental activities of daily life $[11,12]$. In addition, there is the comprehensive geriatric assessment (CGA), considered the gold standard approach for community evaluation. It is usually conducted following existing national strategies in supporting individuals living with frailty [13-15]. The CGA is a multidimensional process that can be performed in a number of healthcare settings to identify medical, social, and functional needs and develop a care plan $[16,17]$.

Primary Health Care (PHC), with its community perspective and longitudinal approach, is the ideal scenario for the early detection of frailty in older adults. Nevertheless, simple evaluation tests need to be incorporated into usual care practice. Early identification would allow targeted support from health and social services to help older individuals improve their quality of life and live autonomously in their homes for as long as possible. In addition to respecting the preferences of most of them
[18], it would provide a more cost-effective alternative to institutionalization.

Adverse outcomes in the progression of frailty include dependency and institutionalization. In Spain, one of the primary care resources available for these individuals is the Home Care programme (HC). It offers comprehensive, continuous health and social attention to individuals in situations of functional decline and/or dependency who cannot attend health centers with the aim of keeping them as long as possible in their home with the corresponding autonomy. The $\mathrm{HC}$ programmes offered by the Spanish PHC cover some $6 \%$ of individuals $>65$ years, the population generally considered to be at a state of advanced frailty or disability [19].

Nevertheless, as frailty advances the complexity of medical attention augments and the caregiver and/or social support may have difficulties maintaining the quality of care. At this point, nursing home $(\mathrm{NH})$ services become the most appropriate resource, despite the considerable financial outlay for both the public health system and the family economy. In our region $\mathrm{NH}$ services cover $3 \%$ of those $>65$ years of age [20].

Most studies have focused on validating instruments to identify and describe the characteristics of frail older individuals [11] whilst other authors have established the determinants of $\mathrm{HC}$ and $\mathrm{NH}$ use [21-23]. The aim of this study is to characterize the factors that will lead to the future inclusion of older, community-dwelling subjects into $\mathrm{HC}$ programmes/ $\mathrm{NH}$ institutionalization, and to develop the corresponding risk prediction models. Both events are related to the progression of frailty, functional decline, and loss of autonomy all of which could be delayed/prevented by an adequate and timely approach to those at risk. These individuals can then benefit from personalized preventive actions in order to remain independent in the community for as long as possible.

\section{Methods}

\section{Study design and setting}

We conducted an eight-year follow-up, multicentre, cohort study in 23 PHC centers in Catalonia, Spain. The $23 \mathrm{PHC}$ were not randomly selected, although special 
care was taken to include PHC with different socioeconomic status as well as urban and rural health centers. Out of the 50 PHC which were invited to participate, a final sample of 23 accepted (20 in urban areas and 3 in rural ones). These PHC belong to the National Health System in Catalonia and are distributed geographically in 3 of the 4 Catalonia provinces, (Barcelona, Lleida and Girona). They serve an assigned population, which varies from 1179 to 29,214 individuals from middle-low to middle-high socioeconomic status. The inclusion period was from October 2004 to June 2005.

\section{Participants}

The cohort was made up of a random sample of 616 subjects $\geq 70$ years of age. Interview participation was turned down by 75 individuals (73\% women) with no age differences compared to the study members. Exclusion criteria included subjects already receiving $\mathrm{HC}$ and $\mathrm{NH}$ services, those presenting severe mental disorders/ terminal illness, and non-residents in the reference area.

\section{Data collection and study variables}

Subjects were randomly selected from the daily schedule of the healthcare professionals taking part in the study, and were included once the informed consent was signed.

Participants were programmed for the interview and the CGA in their corresponding PHC center. The healthcare professionals (nurses and doctors) carried out both the interview and the CGA. The main information collected in interviews through standardized questionnaires included sociodemographic data, physical activity, body mass index (BMI), self-reported health [24], number of hospitalization and falls in the previous year, and prescribed drugs.

The CGA included:

Functional Assessment:

- Basic Activities of Daily Living (BADL) with the Barthel Index [25] (from 0 to 100 points), $<60$ represents moderate/severe dependence.

- Instrumental Activities of Daily Living (IADL) with the Lawton and Brody Index [26], the cut-off points for moderate/severe dependence are $<6$ points for women and $<4$ points for men, respectively.

- Mobility was evaluated with the Timed-up-and-go test (TUGT) [27]. It measures in seconds the time to rise from a chair, walk a distance of $3 \mathrm{~m}$, return to the chair and sit down. It includes aspects of gait, strength, balance, and speed. A score of $>10 \mathrm{~s}$ is usually considered as altered.

\section{Mental health Assessment:}

- Cognitive assessment was measured with the Lobo Mini Cognitive Examination (MCE) [28], the
Spanish validated version of the Folstein Minimental state examination [29] (From 0 to 30 points), the cut-off point for cognitive deterioration is $\leq 23$.

- For evaluation of the affective state, the Yesavage Geriatric Depression Scale (GDS) [30] (from 0 to 15 points) was employed with a cut-off point for probable depression of $>5$.

\section{Biomedical assessment:}

- Nutritional status was measured using the Mini Nutritional Assessment Short Form (MNA-SF) [31] questionnaire (from 0 to 14 points), with a cut-off point $\leq 11$ for risk of malnutrition.

- Near vision was evaluated with the Jaeger Card [32] with a cut-off point of $>20 / 40$ for visual acuity deficit.

- Hearing was assessed with the Handicap Hearing Impairment in the Elderly Screening Version (HHIE-S) [33] (from 0 to 40 points). A cut-off point $\geq 10$ was considered auditory limitation.

- Urinary incontinence was measured with the International Consultation on Incontinence Questionnaire Short Form (ICIQ-SF) [34] (from 0 to 21 points) with a cut-off point $\geq 1$ for the diagnosis of urinary incontinence.

- Morbidities, selected following literature review and consensus by the original study group. The selection criteria were for those conditions most related to the development of frailty, functional limitations, and disability [35, 36]: osteoarticular diseases, cerebrovascular accident with sequelae, Parkinson's disease, acute myocardial infarction or heart failure, chronic obstructive pulmonary disease, severe visual deficit, severe deafness, dementia, recurrent falls or fractures and chronic depression.

\section{Social Assessment:}

- Social vulnerability was evaluated with the SocioFamily Rating Scale of the Elderly (SFRSE) [37] (from 0 to 25 points). It assesses the family, economic situation, housing, social relations, and social support, with a cut-off point $\geq 10$ for social risk.

We gathered the outcome variables during the eightyear follow-up by consulting the electronic primary healthcare records; telephone contacts were made in the case of incomplete information. In addition, we consulted the Central Registry of Catalonia for mortality.

Main outcome variables were:

- Inclusion in an HC program of the PHC: encoded in the electronic primary healthcare records when the service is requested by either the patient or 
healthcare professional, mainly due to considerable mobility difficulties.

- Inclusion in a NH: this encompasses all types of institutions such as nursing homes, long-term care institutions, private or public. It is encoded in the electronic primary healthcare records when a patient is institutionalized with the care relationship usually transferred from the PHC to the institution.

- Mortality: date of death registered in the PHC record and the Central Registry of Catalonia.

\section{Statistical analysis}

Continuous variables were expressed as mean and standard deviation, or as median and interquartile (IQ) range, whenever appropriate. For $\mathrm{HC}$ and $\mathrm{NH}$ outcomes, death prior to these events was considered as a competing risk event, therefore the cumulative incidence function (CIF) of $\mathrm{HC} / \mathrm{NH}$ risk was calculated taking it into consideration. To analyse the effect of baseline predictors for the CIF, we used the Fine-Gray [38] regression model for the sub-distribution hazard (sHR). Clinically meaningful variables showing a significant level in the univariate analysis $(P<0.05)$ were thereafter included in the multivariate model. A backward stepwise method was used to identify independent risk predictors with $\mathrm{P}<0.05$ for the inclusion or deletion criterion. The proportionality assumption of the models was verified using timedependent variables. The discriminative ability of the models was assessed by Harrell's C-index [39]. The internal validity of the final predictive models was tested for 150 bootstrap re-samples. The calibration of models was checked by plotting the observed and predicted probabilities of the model in groups defined by the quartiles of the predicted event probabilities. We estimated a prognostic index for home confinement and institutionalization at 8 years for each patient as the sum of the variables included in the final model multiplied by the $\log$ of the respective sHR. We classified patients using the CIF approach into three groups according to their risk of a $\mathrm{HC} / \mathrm{NH}$ : low, medium, and high, by splitting the index according to tertiles. Data analysis was performed using the statistical R-3.5.1 package. The discrimination and calibration analyses were carried out with the pec package [40].

\section{Results}

Baseline characteristics of the cohort and assessment of frailty dimensions are shown in Tables 1 and 2. The mean baseline age was 76.4 years, $55.5 \%$ were women, $73.5 \%$ did not have complete primary education, and $22 \%$ lived alone (32\% women vs $9.6 \%$ men). Mean BMI was 28.5 and $4.5 \%$ smoked. Health was rated as good by $47.4 \%$ and bad by $6.7 \%$. Patients on average took 5 drugs a day, and $32 \%$ consumed psychotropic ones. At the functional level, the mean Barthel index score was 96.5, the majority were independent for the BADL (62.5\%), and only $15.3 \%$ had moderate/severe dependence. The IADL, measured with the Lawton index, showed that $76.7 \%$ were independent, and only $6.5 \%$ presented moderate/severe dependence. Mobility, measured with TUGT, was $13 \mathrm{~s}$ on average, and $14.4 \%$ of the participants led a sedentary life. At the mental level, the average MCE score was 27/30 points, and the GDS scores showed $19.8 \%$ probable depression.

During follow-up 19.2\% $(n=118)$ of the 616 participants entered a HC programme (30.6 incidence per 1000 person-years), while $8.2 \%(n=51)$ were admitted to a NH one (13.1 incidence per 1000 person-years). Of those admitted to a $\mathrm{NH}, 31.5 \%(n=17)$ had previously been in a HC. Of the 616, mortality during follow-up was $15.4 \%(n=95)$ for participants presenting no event, and $46.2 \%(n=78)$ for those who were in either a $\mathrm{HC}$ or $\mathrm{NH}$ programme. During follow-up $4.5 \%(n=28)$ was lost with a greater proportion of men $(64 \%, p<0.05)$. However, there were no statistically significant differences in the rest of the main variables between those who completed the study and those who did not (Fig. 1).

The median follow-up was 91.8 months (IQ: 58.197.7) and 92.3 months (IQ: 59.7-97.9) for the HC and $\mathrm{NH}$ subjects, respectively.

Table 1 shows the bivariate sHRs of admission to $\mathrm{HC}$ and NC programmes during the eight-year follow-up period according to baseline variables.

Comparing those who entered a $\mathrm{HC}$ programme with those who did not, $\mathrm{HC}$ incidence increased with age ( 78.9 years versus 75.2 years, sHR $=1.1$ ), sedentary life style $(22.9 \%$ versus $11.3 \%$, sHR $=2.4)$, and poor self-perceived health $(12.7 \%$ versus $6.7 \%$, sHR $=$ 2.3).

Table 2 shows the bivariate sHRs of admission to HC and $\mathrm{NC}$ programmes during the eight-year follow-up period according to the geriatric assessment.

Comparing those who entered a $\mathrm{HC}$ programme with those who did not, $\mathrm{HC}$ incidence increased with worse functional status, Barthel index (94.1 versus 97.5, sHR = $1.0)$, and Lawton and Brody index, in light (22.2\% versus $13.4 \%$, sHR $=1.7)$ and moderate dependence $(15.4 \%$ versus $3.2 \%, \mathrm{sHR}=4.8$ ). It also augmented in individuals with worse mobility (mean TUGT 16.2 versus 11.8, sHR $=1.1$ ); worse cognitive scores (mean score 26.2 versus $27.4, \mathrm{sHR}=0.9$ ); worse affective state (mean 4.3 versus 3.6 , sHR $=1.1)$; urinary incontinence $(59.3 \%$ versus $40.5 \%$, sHR $=1.8$ ); and higher social risk (mean 9.4 versus $8.7, \mathrm{sHR}=1.1$ ).

Admission to a $\mathrm{NH}$ programme was associated with age (mean 78.7 versus 75.8, sHR $=1.1$ ); living alone ( $47.1 \%$ versus $19.4 \%$, sHR $=2.8)$; and greater drug consumption (mean 6.6 versus 4.6 , $\mathrm{sHR}=1.2$ ). 


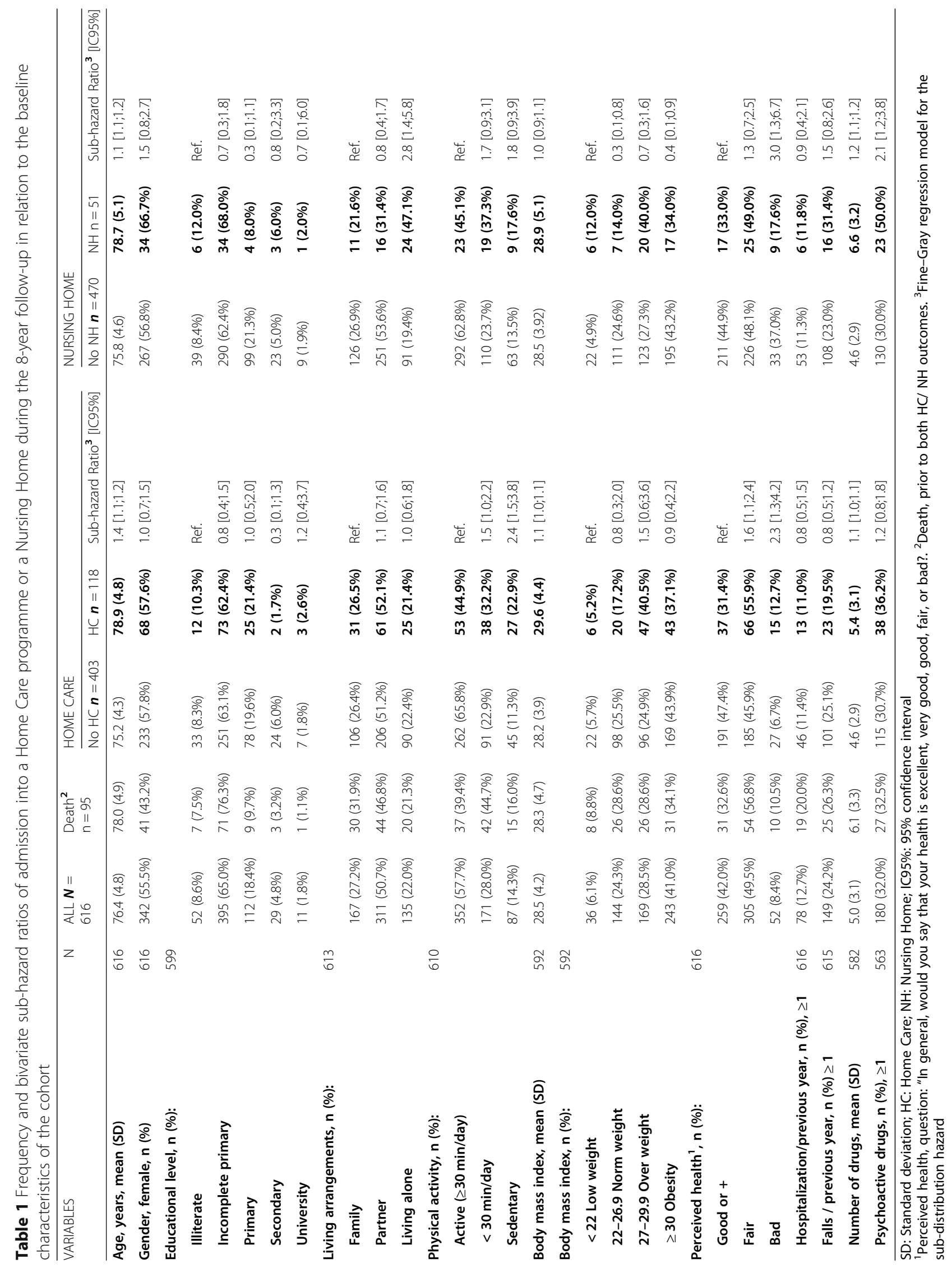


Table 2 Frequency and bivariate sub-hazard ratios of admission into a Home Care programme or a Nursing Home during the 8-year follow-up in relation to the baseline Comprehensive Geriatric Assessment

\begin{tabular}{|c|c|c|c|c|c|c|c|c|c|}
\hline \multirow[t]{2}{*}{ VARIABLES } & \multirow[t]{2}{*}{$\mathrm{N}$} & \multirow{2}{*}{$\begin{array}{l}A L L \\
N=616\end{array}$} & \multirow{2}{*}{$\begin{array}{l}\text { Death } \\
\mathrm{n}=95\end{array}$} & \multicolumn{3}{|l|}{ HOME CARE } & \multicolumn{3}{|c|}{ NURSING HOME } \\
\hline & & & & $\begin{array}{l}\text { No HC } \\
n=403\end{array}$ & $\begin{array}{l}\mathrm{HC} \\
\mathrm{n}=118\end{array}$ & $\begin{array}{l}\text { Sub-hazard } \\
\text { Ratio }^{\mathbf{1 3}} \\
\text { [C195\%] }\end{array}$ & $\begin{array}{l}\text { No NH } \\
n=470\end{array}$ & $\begin{array}{l}\mathrm{NH} \\
\mathrm{n}=51\end{array}$ & $\begin{array}{l}\text { Sub-hazard } \\
\text { Ratio }{ }^{\mathbf{3}} \\
\text { [C195\%] }\end{array}$ \\
\hline BADL (Barthel ${ }^{1}$ ), mean (SD) & 616 & $96.5(7.0)$ & $95.5(9.8)$ & $97.5(5.7)$ & $94.1(7.7)$ & $1.0[1.0 ; 1.0]$ & $97.1(5.3)$ & $93.1(12.1)$ & $1.0[1.0 ; 0.98]$ \\
\hline IADL (Lawton \& Brody $\left.{ }^{2}\right), n$ (\%) & 615 & & & & & & & & \\
\hline Independent & & $472(76.7 \%)$ & $63(66.3 \%)$ & $336(83.4 \%)$ & $73(62.4 \%)$ & Ref. & $373(79.5 \%)$ & $36(70.6 \%)$ & Ref. \\
\hline Mild Dependence & & $103(16.7 \%)$ & $23(24.2 \%)$ & $54(13.4 \%)$ & $26(22.2 \%)$ & $1.7[1.1 ; 2.6]$ & $73(15.6 \%)$ & $7(13.7 \%)$ & $0.9[0.4 ; 2.1]$ \\
\hline Moderate + Severe Dependence & & $40(6.5 \%)$ & $9(9.5 \%)$ & $13(3.2 \%)$ & $18(15.4 \%)$ & $4.8[2.8 ; 8.3]$ & $23(4.9 \%)$ & $8(15.7 \%)$ & $4.5[2.0 ; 9.9]$ \\
\hline $\begin{array}{l}\text { Mobility assessment } \\
\text { (Timed-up-and-go test }{ }^{3} \text { ), } \\
\text { mean (SD) }\end{array}$ & 599 & $13.0(6.8)$ & $14.6(7.4)$ & $11.8(5.5)$ & $16.2(9.0)$ & $1.1[1.0 ; 1.1]$ & $12.4(6.4)$ & $15.5(8.4)$ & $1.1[1.0 ; 1.1]$ \\
\hline $\begin{array}{l}\text { Cognitive status }\left(\mathrm{MEC}^{4}\right) \\
\text { mean }(\mathrm{SD})\end{array}$ & 614 & $27.0(3.7)$ & $26.6(3.6)$ & $27.4(3.6)$ & $26.2(3.9)$ & $0.9[0.9 ; 1.0]$ & $27.3(3.6)$ & $25.6(3.8)$ & $0.9[0.9 ; 1.0]$ \\
\hline $\begin{array}{l}\text { Affective status }\left(\mathrm{GDS}^{5}\right) \\
\text { mean (SD) }\end{array}$ & 607 & $3.8(3.3)$ & $4.2(3.2)$ & $3.6(3.3)$ & $4.3(3.1)$ & $1.1[1.0 ; 1.1]$ & $3.6(3.2)$ & $5.1(3.8)$ & $1.1[1.0 ; 1.2]$ \\
\hline 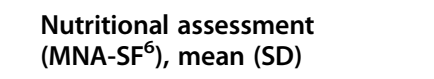 & 604 & $12.9(1.6)$ & $12.6(1.8)$ & $13.0(1.6)$ & $12.8(1.6)$ & $0.9[0.9 ; 1.0]$ & $13.0(1.6)$ & $12.6(1.8)$ & $0.9[0.8 ; 1.0]$ \\
\hline $\begin{array}{l}\text { Visual impairment } \\
\left(\text { Jaeger } \text { Card }^{7}\right), n(\%)\end{array}$ & 611 & 195 (31.9\%) & 34 (35.8\%) & 112 (28.0\%) & 49 (42.2\%) & $1.7[1.2 ; 2.4]$ & $143(30.6 \%)$ & 18 (36.7\%) & $1.3[0.7 ; 2.4]$ \\
\hline 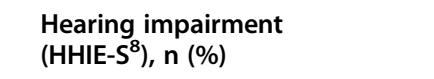 & 612 & 121 (19.8\%) & $21(22.1 \%)$ & 71 (17.7\%) & $29(25.0 \%)$ & $1.4[0.9 ; 2.1]$ & 89 (19.1\%) & $11(21.6 \%)$ & $1.2[0.6 ; 2.3]$ \\
\hline $\begin{array}{l}\text { Urinary incontinence } \\
\left(\mathrm{ICIQ}^{-} \mathrm{SF}^{9}\right), \mathrm{n}(\%)\end{array}$ & 615 & 277 (45.0\%) & 44 (46.3\%) & $163(40.5 \%)$ & 70 (59.3\%) & $1.8[1.3 ; 2.7]$ & 199 (42.4\%) & 34 (66.7\%) & $2.5[1.4 ; 4.5]$ \\
\hline $\begin{array}{l}\text { Number of morbidities }{ }^{10} \\
\text { mean (SD) }\end{array}$ & 616 & $0.8(0.9)$ & $0.9(1.1)$ & $0.7(0.9)$ & $0.9(0.8)$ & $1.1[1.0 ; 1.3]$ & $0.7(0.8)$ & $1.0(1.3)$ & $1.3[1.1 ; 1.6]$ \\
\hline $\begin{array}{l}\text { Social risk (Social-familial } \\
\text { evaluation scale }{ }^{11} \text { ), } \\
\text { mean (SD) }\end{array}$ & 614 & $8.8(2.7)$ & $8.7(2.8)$ & $8.7(2.7)$ & $9.4(2.7)$ & $1.1[1.0 ; 1.2]$ & 8.7 (2.6) & $10.7(3.2)$ & $1.2[1.1 ; 1.3]$ \\
\hline
\end{tabular}

SD: Standard deviation; HC: Home Care; NH: Nursing Home; Cl95\%: 95\% confidence interval

${ }^{1}$ Basic Activities of the Daily Living (BADL) Barthel Index (from 0 to 100 points), below 60 represents moderate/ severe dependence. ${ }^{2}$ Instrumental Activities of the Daily Living (IADL) Lawton and Brody Index, with dependence cut-off points for women $<8$ points (from 0 to 8 points) and men $<5$ points (from 0 to 5 points). ${ }^{3}$ Timed-up-and-go test (TUGT) The score of $>10 \mathrm{~s}$ was considered altered. ${ }^{4}$ Mini Cognitive Examination (MEC), (from 0 to 30 points), cut-off point for cognitive deterioration $\leq 23 .{ }^{5}$ Geriatric Depression Scale (GDS) Yesavage Scale (from 0 to 15 points), cut-off point for probable depression $>5$. ${ }^{6}$ Mini Nutritional Assessment Short Form (MNA-SF) (from 0 to 14 points), cut-off point $\leq 11$ for risk of malnutrition. ${ }^{7}$ Jaeger Card, point $>20 / 40$ visual acuity deficit. ${ }^{8}$ Handicap Hearing Impairment in the Elderly Screening Version (HHIE-S) (from 0 to 40 points) (ref). The cut-off point $\geq 10$ was considered an auditory limitation. ${ }^{9}$ International Consultation on Incontinence Questionnaire Short Form (ICIQ-SF) (from 0 to 21 points) with a cut-off point $\geq 1$ for the diagnosis of urinary incontinence.

${ }^{10}$ Morbidities related to frailty, including: cerebrovascular accident with sequelae, Parkinson's disease, osteoarticular diseases, severe visual deficit, dementia, acute myocardial infarction or heart failure, chronic obstructive pulmonary disease, recurrent falls or fractures, severe deafness and chronic depression. ${ }^{11}$ Socio-Family Rating Scale of the Elderly (SFRSE) (from 0 to 25 points) which assesses family, economic situation, housing, social relations, and social support, with a cut-off point $\geq 10$ for social risk. ${ }^{12}$ Death, previous to both $\mathrm{HC} / \mathrm{NH}$ outcomes. ${ }^{13}$ Fine-Gray regression model for the sub-distribution hazard

Functional impairment in BADL was related to $\mathrm{NH}$ and the Barthel index (mean 93.1 versus 97.1, sHR =1.0). Unlike a $\mathrm{HC}$, however, $\mathrm{NH}$ entry was only associated with the highest degree of dependence in the Lawton and Brody index (moderate/severe dependence, with 15.7\% versus $4.9 \%$, sHR $=4.5)$. It was also related to worse mobility (longer TUGT time, mean 15.5 versus 12.4 , sHR = 1.1); worse cognitive scores (mean 25.6 versus 27.3 , sHR $=0.9$ ) and risk of depression (mean 5.1 versus $3.6, \mathrm{sHR}=1.1$ ).

We found a higher risk of $\mathrm{NH}$ admission for urinary incontinence $(66.74 \%$ versus $42.4 \%$, sHR $=2.5)$; higher number of specific morbidities (mean 1.0 versus 0.7 , $\mathrm{SHR}=1.3$ ); and social risk (higher score on the socio-familial assessment scale of the elderly, mean 10.7 versus $8.7, \mathrm{sHR}=1.2$ ).
A complementary, bivariate sub-analysis was carried out between the participant's social risk and the occurrence of any events (NH, HC; data not shown). We observed a dose-response association between increasing social risk and being first admitted to a HC programme; with a still higher baseline social risk, entering a $\mathrm{NH}$ one: Finally, the highest baseline social risk was associated with first a $\mathrm{HC}$ programme and later a $\mathrm{NH}$ facility.

The multivariate adjusted model showed that the incidence risk of a $\mathrm{HC}$ entry was associated with older age, dependence on the IADL (moderate/severe dependence), and slow gait measured by TUGT. There was a significant association between the risk of being admitted to a $\mathrm{NH}$ programme and older age, dependence on the IADL 


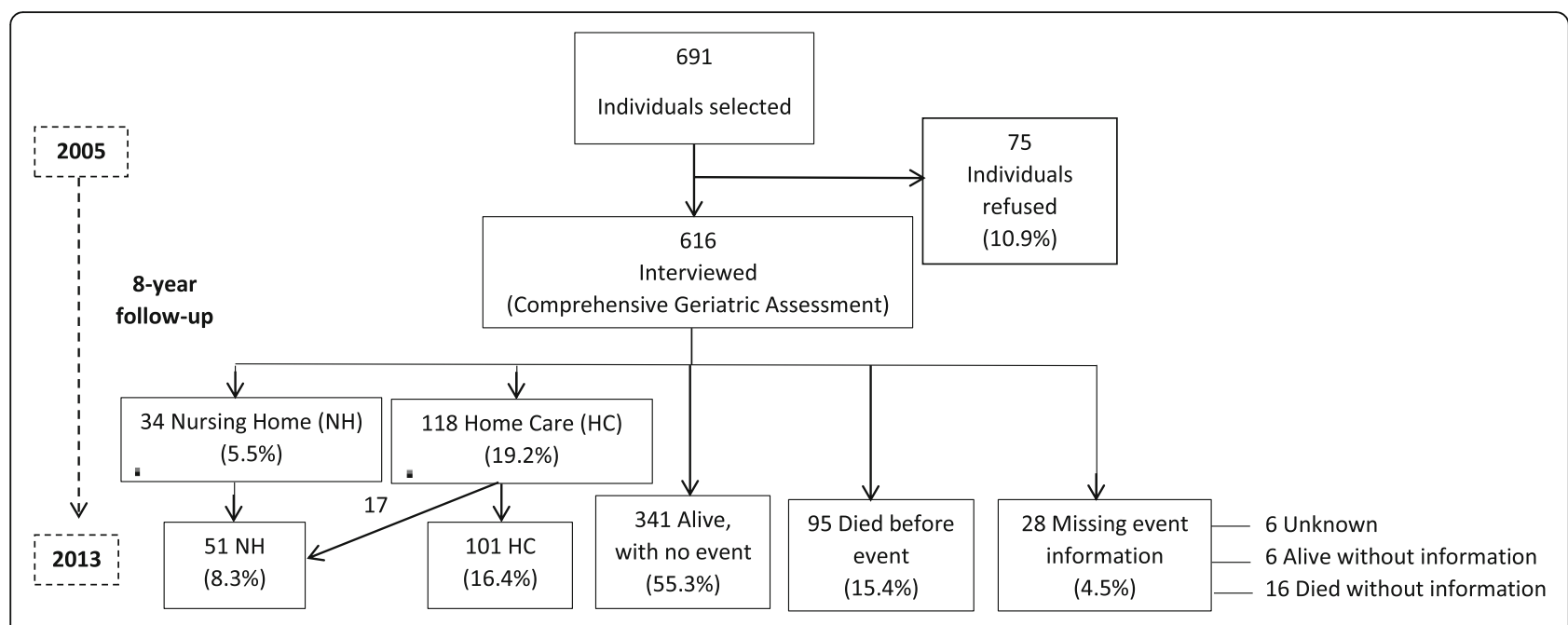

Fig. 1 Flow diagram showing the study follow-up

(moderate/severe), more prescriptions, and the presence of social risk, see Table 3.

Based on the results of the multivariate analyses, we constructed two prediction models according to the risk of inclusion in a $\mathrm{HC} / \mathrm{NH}$. Subjects with a $\mathrm{HC}$ risk were classified into three groups: lower risk with a prognostic index (PI) between 7.5 and 8.3; medium risk, between 8.4 and 8.9; and higher risk $>9.0$. The $\mathrm{NH}$ model was also categorized into three groups: lower risk between 7.9 and 9.5; medium risk between 9.6 and 10.2; and higher risk PI $>10.3$, see Table 3 .
The calibration plot showed that both models ( $\mathrm{HC}$ and $\mathrm{NH}$ ) presented a good calibration for predicting risk outcomes. In addition, discrimination was good for a $\mathrm{HC}(\mathrm{C}$-index $=0.7)$ and moderate for a $\mathrm{NH}(\mathrm{C}$-index $=$ $0.7)$, see Fig. 2.

Figure 3 depicts the cumulative incidence for each of these prognostic groups for the two events. For a $\mathrm{HC}$ in the lower risk group the cumulative incidence was 10.0 per 1000 patients-year; for the medium risk one it was 25.6 per 1000 patients-year; and for the higher risk one 63.1 per 1000 patients-year $(p<0.001)$. For a NH in the

Table 3 Multivariate Competitive Risk Models for a Home Care and Nursing Home admission, prognostic index functions, and risk classification

\begin{tabular}{|c|c|c|c|c|c|}
\hline \multicolumn{3}{|l|}{ HOME CARE (HC) } & \multicolumn{3}{|l|}{ NURSING HOME (NH) } \\
\hline & Sub Hazard Ratio [C195\%] & $\boldsymbol{p}$-value & & Sub Hazard Ratio [C195\%] & $p$-value \\
\hline Age (years) & $1.1[1.1-1.2]$ & $<0.001$ & Age (years) & $1.1[1.0-1.2]$ & 0.002 \\
\hline IADL: Independent & 1 & & IADL: Independent & 1 & \\
\hline IADL: Mild Dependence & $1.5[1.0-2.4]$ & 0.083 & IADL: MIId Dependence & $0.6[0.2-1.5]$ & 0.250 \\
\hline IADL: Moderate Dependence or + & $2.8[1.4-5.6]$ & 0.005 & IADL: Moderate Dependence or + & $2.6[1.0-6.8]$ & 0.045 \\
\hline TUGT (seconds) & $1.0[1.0-1.1]$ & 0.024 & - & - & - \\
\hline \multirow[t]{2}{*}{-} & - & - & Number of drugs & $1.1[1.0-1.2]$ & 0.019 \\
\hline & & & SFRSE (points) & $1.2[1.1-1.2]$ & $<0.001$ \\
\hline
\end{tabular}

\section{PROGNOSTIC INDEX FUNCTION (PI)}

\section{HC PI}

PI: $0,107^{*}$ Age (years) $+0.412^{*}$ Mild instrumental dependence (IADL) + $1013^{*}$ Moderate instrumental dependence (includes severe and total) (IADL) + 0,0331*TUGT (seconds)

\section{Risk group}

•Lower risk group: PI 7.5-8.3

-Medium risk group: PI 8.4-8.9

-Higher risk: $\mathrm{Pl} \geq 9.0$

\section{NH PI}

PI: $0,106^{*}$ Age (years)- $0.551^{*}$ Mild instrumental dependence (IADL) + $0.971 *$ Moderate instrumental dependence (includes severe and total) $\left(\right.$ IADL) $+0.097 *$ Number of drugs $+0.165{ }^{*}$ SFRSE (points)

\section{Risk group}

•Lower risk group: PI 7.9-9.5

-Medium risk group: PI 9.6-10.2

•Higher risk: $\mathrm{Pl} \geq 10.3$

IADL: Instrumental Activities of Daily Living; TUGT: Timed Get Up and Go Test; SFRSE: Socio-Family Rating Scale of the Elderly; HC: Home Care; NH: Nursing Home; C195\%: 95\% confidence interval 


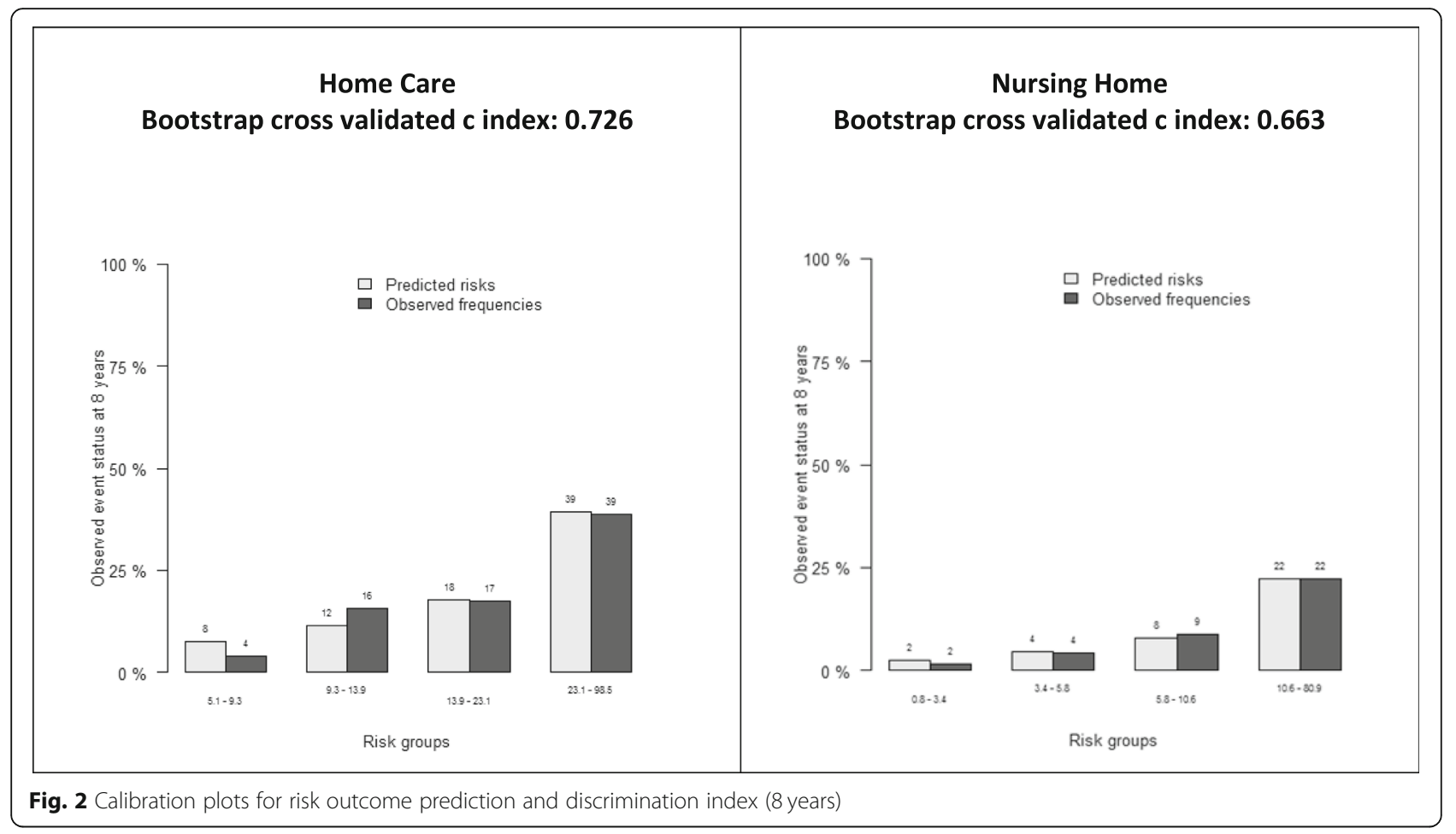

lower risk group the incidence was 1.9 per 1000 patients-year; the medium risk one was 4.2 per 1000 patients-year; and the higher risk one was 32.9 per 1000 patients-year $(\mathrm{p}<0.001)$.

\section{Discussion}

\section{Incidence of home care and nursing home entry}

In this eight-year cohort study, a follow-up of more than 95\% participants was obtained, with 19\% entering home care programmes, and $8 \%$ geriatric nursing homes, outcomes that are generally associated with advanced frailty, especially when not addressed promptly and adequately. Health service utilization is influenced by numerous aspects, including sociodemographic, organizational, and sociocultural ones. Nevertheless, it is beyond the scope of this paper to compare $\mathrm{HC} / \mathrm{NH}$ rates among countries or different health systems. We used, instead, these events as measures of health outcomes associated with the loss of functionality and independence. However, regarding $\mathrm{HC}$, although difficult to compare, similar rates were observed between homebound incidence in Japan [41] (32.1 per 1000 individuals/year) and that of our study (30.6 per individual/year). With respect to $\mathrm{NH}$ entry, we found lower rates than those reported by the USA [42], $16.1 \%$ in 2 years; but closer to Germany, with rates of $4.7 \%$ in a three-year follow-up [43]. Again, institutionalization rates differ among countries, depending on organizational aspects, the availability of longterm beds and the responsibility for the care of disabled older individuals by different actors. Our rates of institutionalization are low, this could be explained by the fact that in southern European cultures the involvement of the family in the care of older adults is considerable, whether for cultural or economic reasons $[44,45]$.

\section{Risk factors Age and sex}

In our results, increasing age was the main predisposing factor associated with frailty and both an $\mathrm{HC}$ and $\mathrm{NH}$ placement. Although women had a higher incidence of $\mathrm{NH}$ inclusion, it was not a statistically significant predictor. The higher life expectancy of women, and the greater percentage of their living alone, could explain this trend [46].

\section{Functional status}

We observed that IADL deterioration was associated with both a $\mathrm{HC}$ and $\mathrm{NH}$. The ability to perform instrumental activities of daily life autonomously is essential to live at home independently. It is, therefore, a relevant measure to take into account when predicting the path to functional decline and dependence. We found that even mild dependence in the IADL was associated with a future $\mathrm{HC}$, and moderate to severe dependence with $\mathrm{NH}$ entry. IADL impairment has been described as a potential marker of frailty [47], implying losses in different functioning domains [48]. There is, however, controversy with respect to disability and its inclusion in the definition of frailty [49]. Nevertheless, early stages of IADL impairment could be useful in detecting individuals at risk, it is an easy measure to collect and has a long- 


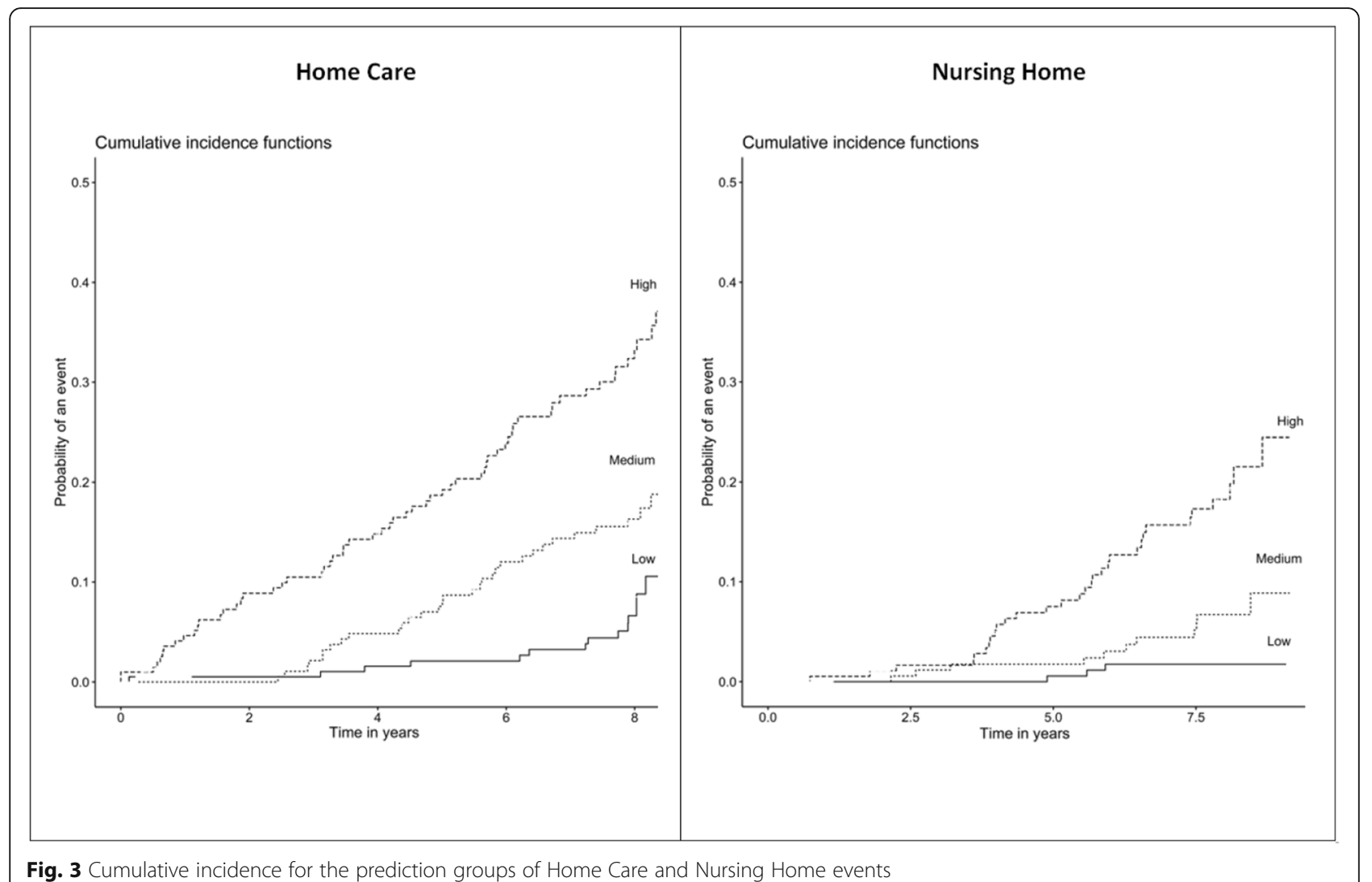

established tradition in PHC settings. Our sample included very few subjects with dependence in basic activities of daily living as it was composed of communitydwelling, independent individuals. BADL thus had no impact on the prediction models.

\section{Mobility}

We measured mobility with the TUGT. It has been shown to have high sensitivity for identifying frailty [11], moreover, as it is a simple test requiring little equipment and space, the TUGT is a valuable tool in a clinical setting. Savva et al. [50] found that a cut-off point of more than $16 \mathrm{~s}$ was optimum to identify the frail population. Our results concur, we observed a mean score of $16.2 \mathrm{~s}$ for subjects entering a $\mathrm{HC}$ programme, and $15.5 \mathrm{~s}$ for a $\mathrm{NH}$ one. Due to the fact that the TUGT has been used as a proxy measure of frailty [50] and subsequent functional decline, it is a relevant factor in a $\mathrm{HC}$ prediction model.

\section{Polypharmacy}

Polypharmacy is a measure of medication-associated frailty, irrespective of the number of comorbidities and their severity [51]. It is associated with increased rates of falls [52] and hospitalization, disability, and mortality [53]. In our sample, polypharmacy, collected from the electronic primary healthcare records, was a prevailing factor. Some $52 \%$ of the participants had more than 4 prescribed drugs which was higher than in other studies reporting a prevalence based on health surveys of between 26 and 40\% [54]. It was, however, closer to those authors employing electronic healthcare records [55] who observed over $50 \%$. In our study, polypharmacy predicted $\mathrm{NH}$ entry, a fact that might be related to multimorbidity in addition to adverse drug reactions/ interactions, and greater risk of falls, and negative health outcomes [56].

Particular emphasis should be placed on psychoactive drugs as $50 \%$ of those entering a $\mathrm{NH}$ were taking them. Moreover, inappropriate polypharmacy is a key issue to address in order to improve outcomes in older adults [57] by means of active medication reviews and deprescription processes with tools such as STOPP START criteria and other available strategies [58].

\section{Social vulnerability}

We observed that whilst living alone had no effect on the need for an $\mathrm{HC}$ it did influence $\mathrm{NH}$ entry $(\mathrm{sHR}=2.8)$, a finding that has been already described in other countries [59-62]. Employing an exhaustive socio-family situation measure, the SFRSE scale, we found a strong association between greater social risk and a higher institutionalization rate, irrespective of functional status or 
comorbidities. It appears as one of the predictors in a $\mathrm{NH}$ entry equation highlighting the importance of social support and environment in maintaining the capacity to live in the community in one's home. Social and caregiver networks could help circumvent institutionalization, as has been observed in various studies that only take either living arrangements or caregiver networks into account $[63,64]$. The need to assess the social sphere of frail older adults is evident [65]. Indeed, as the issue of social frailty is increasingly conceptualized [66], the design of interventions to improve social support resources and promote inclusion of older adults will become essential in granting their preferences for living in the community, and thus improving quality of life.

\section{Other factors}

Cognitive impairment and dementia are factors classically described as being related to $\mathrm{NH}$ placement [61]. Whilst we observed a bivariate association between cognitive status and adverse events it was not included in the final model. This was due to the low prevalence of dementia in our free-living, community-dwelling population. As we lacked a longitudinal measure of the incidence of cognitive impairment in our sample, we could not test the association with enough statistical power. The same pattern of bivariate association was also reported for depression, nutritional risk, and urinary incontinence. The latter is additionally usually found as a strong gender-specific predictor [67], negatively affecting daily life although our final model did not include it.

\section{Strengths and limitations}

Few longitudinal studies can be found in the literature analysing the transition of frail older adults from the commencement of their requiring home care to later nursing home placement, both outcomes related to functional decline and loss of autonomy. Our cohort had an excellent follow-up rate, up to $95 \%$ of the sample, and was representative of the older patients attended in primary healthcare in Catalonia, around $12.6 \%$ of the total patient population. Although our external validity was limited to those who sought medical assistance at the PHC it should be noted that this was not a health survey aimed at representing all the older population in this region. Moreover, most of these individuals in Spain seek medical assistance in the public health sector.

Despite the fact that our models included the main CGA variables there might have been other factors influencing an $\mathrm{HC} / \mathrm{NH}$ admission. Nevertheless, the CGA is comprised of the most important known dimensions, and they were measured using standardised, validated questionnaires and scales. Finally, although an extensive follow-up was performed, changes in baseline variables during follow-up were not analyzed as it was a prediction model based on the initial situation of the sample.

\section{Conclusions}

Prognostic models established with comprehensive geriatric assessments can predict the commencement of the need for $\mathrm{HC}$ and subsequent $\mathrm{NH}$ entry in communitydwelling, older adults. Our findings underline the necessity to measure functional capacity, mobility, inappropriate prescriptions, and social aspects of older adults in primary care settings where they can be offered holistic, longitudinal assessments, and tailored interventions.

Such models could also be useful for the risk classification of frail older adults and in the planning of health care policies.

\section{Recommendations}

- Due to the relevance of mobility and instrumental activities of daily living in the prediction of adverse outcomes, community interventions based on physical and functional exercises should be prioritised to improve/maintain independence and quality of life in older adults $[68,69]$.

- Tackling polypharmacy and inappropriate prescriptions through deprescription processes at the primary care level should also be prioritised $[69,70]$.

- Interventions to improve social resources and promote social support networks and inclusion in the community would improve the quality of life of older adults. Moreover, they would enhance the efficiency of the health system and, given the high cost of residential centres, ease the financial burden for both for families and society [70].

\section{Abbreviations}

BADL: Basic Activities of the Daily Living; BMI: Body mass index; CIF: Cumulative incidence function; CGA: Comprehensive Geriatric Assessment; GDS: Geriatric Depression Scale; HC: Home care; HHIES: Handicap Hearing Impairment in the Elderly Screening Version; IADL: Instrumental Activities of the Daily Living; ICIQ-SF: International Consultation on Incontinence Questionnaire Short Form; IQ: Interquartile; MCE: Mini Cognitive Examination; MNA-SF: Mini Nutritional Assessment Short Form; NH: Nursing home; PHC: Primary Health Care; SFRSE: Socio-Family Rating Scale of the Elderly; SHR: Subdistribution hazard; TUGT: Timed-up-andgo test

\section{Acknowledgments}

We would like to thank the study participants and the healthcare professionals who helped us contact them.

\section{Authors' contributions}

FC, FO coordinated the study. FC, FO were involved in the study conduct. $\mathrm{RA}, \mathrm{FO}, \mathrm{FC}, \mathrm{MP}$ were involved in the analyses and interpretation. FC, FO, MP, RA were involved in drafting the manuscript. All authors read and approved the final manuscript.

\section{Funding}

This work was supported by ISCIII, Ministry of Economy and Competitiveness, Spain, with a grant for research projects on health (PI031655) and the 7th 
Primary Care Research of Barcelona Region Award. The funders had no role in study design, data collection and analysis, decision to publish, or preparation of the manuscript.

\section{Availability of data and materials}

The dataset supporting the conclusions of this article is available in the Open Science Framework repository, in [https://osf.io/sqty8/].

\section{Ethics approval and consent to participate}

Research was performed in accordance with the Declaration of Helsinki. Ethics approval for the study was received from: The Ethical Committee on Clinical Research IDIAP Jordi Gol, approval number P11/75. All study participants gave written informed consent.

\section{Consent for publication}

Not applicable.

\section{Competing interests}

None declared.

\section{Author details}

'Centre d'Atenció Primària Sant Martí, Gerència Territorial de Barcelona, Institut Català de la Salut, Barcelona, Spain. ${ }^{2}$ Unitat de Suport a la Recerca Barcelona, Fundació Institut Universitari per a la recerca a l'Atenció Primària de Salut Jordi Gol i Gurina (IDIAPJGol), IDIAP Jordi Gol. Gran Via Corts Catalanes 587, Àtic., 08007 Barcelona, Spain. ${ }^{3}$ Gerència Territorial de Barcelona, Institut Català de la Salut, Barcelona, Spain. ${ }^{4}$ Department of Clinical Foundations, Faculty of Medicine, Barcelona University, Barcelona, Spain. ${ }^{5}$ Department of Public Health History of Science and Gynecology, Miguel Hernández University of Elche, Alicante, Spain. ${ }^{6}$ Center for Biomedical Research in Epidemiology and Public Health Network (CIBERESP), Madrid, Spain.

Received: 10 October 2019 Accepted: 29 July 2020

Published online: 06 August 2020

\section{References}

1. United Nations, Department of Economic and Social Affairs, Population Division. World Population Prospects 2019: Highlights. ST/ESA/SER.A/423. Available from: https://population.un.org/wpp/Publications/Files/WPP2019_ Highlights.pdf. Accessed 7 July 2020.

2. Kojima G. Frailty as a predictor of disabilities among community-dwelling older people: a systematic review and meta-analysis. Disabil Rehabil. 2017; 39(19):1897-1908. doi:https://doi.org/10.1080/09638288.2016.1212282.

3. Abellán A, Ayala A, Pérez J, Pujol R. Un perfil de las personas mayores en España, 2018. Indicadores estadísticos básicos. Madrid, 2018. Informes Envejecimiento en red $\mathrm{n}^{\circ}$ 17, 34p. Available from: http://envejecimiento.csic. es/documentos/documentos/enred-indicadoresbasicos18.pdf. Accessed 7 July 2020.

4. Albarrán I, Alonso P. La población dependiente en España: estimación del número y coste global asociado a su cuidado. Estudios de Economía. 2009; 36(2):127-63.

5. Rodríguez-Mañas L, Féart C, Mann G, Viña J, Chatterji S, Chodzko-Zajko W, et al. Searching for an operational definition of frailty: a Delphi method based consensus statement. The frailty operative definition-consensus conference project. J Gerontol A Biol Sci Med Sci. 2013;68(1):62-7. https:// doi.org/10.1093/gerona/gls119.

6. Victor CR, Healy J, Thomas A, Seargeant J. Older patients and delayed discharge from hospital. Health Soc Care Community. 2000;8(6):443-52. https://doi.org/10.1046/j.1365-2524.2000.00270.

7. Luppa M, Luck T, Weyerer S, König HH, Brähler E, Riedel-Heller SG. Prediction of institutionalization in the elderly. A systematic review. Age Ageing. 2010;39(1):31-8. https://doi.org/10.1093/ageing/afp202.

8. Ahmad R, Bath PA. Identification of risk factors for 15-year mortality among community-dwelling older people using cox regression and a genetic algorithm. J Gerontol A Biol Sci Med Sci. 2005;60(8):1052-8. https://doi.org/ 10.1093/gerona/60.8.1052.

9. Fried LP, Tangen CM, Walston J, Newman AB, Hirsch C, Gottdiener J, et al. Frailty in older adults: evidence for a phenotype. J Gerontol A Biol Sci Med Sci. 2001;56(3):M146-56. https://doi.org/10.1093/gerona/56.3.m146.
10. Rockwood K, Mitnitski A. Frailty in relation to the accumulation of deficits. J Gerontol A Biol Sci Med Sci. 2007;62:722-7. https://doi.org/10.1093/gerona/ 62.7.722.

11. Clegg A, Rogers L, Young J. Diagnostic test accuracy of simple instruments for identifying frailty in community-dwelling older people: a systematic review. Age Ageing. 2015;44(1):148-52. https://doi.org/10.1093/ageing/ afu157.

12. Apostolo J, Cooke R, Bobrowicz-Campos E, Santana S, Marcucci M, Cano A, et al. Predicting risk and outcomes for frail older adults: an umbrella review of frailty screening tools. JBI Database System Rev Implement Rep. 2017;15: 1154-208.

13. NHS England/LTC Team. Toolkit for General Practice in Supporting Older People Living With Frailty. Update to 2014 document. Available from: https://www.england.nhs.uk/wp-content/uploads/2017/03/toolkit-generalpractice-frailty-1.pdf Accessed 7 July 2020.

14. Documento de consenso sobre prevención de fragilidad y caídas en la persona mayor. Estrategia de Promoción de la Salud y Prevención en el SNS. Madrid: Ministerio de Sanidad, Servicios Sociales e Igualdad; 2014. Available from: https://www.mscbs.gob.es/profesionales/saludPublica/ prevPromocion/Estrategia/docs/FragilidadyCaidas_personamayor.pdf Accessed 7 July 2020

15. Supporting routine frailty identification and frailty through the GP Contract 2017/2018. NHS England. Available from: https://www.england.nhs.uk/ publication/supporting-routine-frailty-identification-and-frailty-through-thegp-contract-20172018/. Accessed 7 July 2020.

16. Parker SG, McCue P, Phelps K, McCleod A, Arora S, Nockels K, et al. What is comprehensive geriatric assessment (CGA)? An umbrella review. Age Ageing. 2018;47(1):149-55. https://doi.org/10.1093/ageing/afx166.

17. Pilotto A, Cella A, Pilotto A, Daragjati J, Veronese N, Musacchio C, et al. Three Decades of Comprehensive Geriatric Assessment: Evidence Coming From Different Healthcare Settings and Specific Clinical Conditions. J Am Med Dir Assoc. 2017;18(2):192.e1-192.e11. https://doi.org/10.1016/j.jamda. 2016.11.004.

18. Primero las personas: Cuidar como nos gustaría ser cuidados. Resultados de la Encuesta sobre cuidados. Obra social "la Caixa". Fundación Matia Instituto Gerontológico. 2016. Available from: https://www.matiainstituto.net/sites/ default/files/archivospdf/resumen-de-la-encuesta-i-primero-personas-cuidarcomo-nos-gustaria-ser-cuidados-i.pdf. Accessed 7 July 2020.

19. Generalitat de Catalunya. CatSalut. Ús de recursos i despesa sanitària dels pacients en atenció domiciliària. Any 2016. Informes breus. Número 13. 2018. Available from: http://hdl.handle.net/11351/3457. Accessed 7 July 2020.

20. Las Personas Mayores en España. Informe 2016. Datos Estadísticos Estatales y por Comunidades Autónomas. Ministerio de Sanidad, Servicios Sociales e Igualdad 2017. 518p. Available from: http://feafesgalicia.org/img/ documentacion/estudios/Informe_2016_personas_mayores.pdf . Accessed 7 July 2020.

21. Hollander MJ, Chappell NL. A comparative analysis of costs to government for home care and long-term residential care services, standardized for client care needs. Can J Aging. 2007;26:149-61. https://doi.org/10.3138/cja. 26.suppl_1.149.

22. Slobbe LCJ, Wong A, Verheij RA, van Oers HAM, Polder JJ. Determinants of first-time utilization of long-term care services in the Netherlands: an observational record linkage study. BMC Health Serv Res. 2017;17(1):626. https://doi.org/10.1186/s12913-017-2570-z.

23. Young C, Hall AM, Gonçalves-Bradley DC, Quinn TJ, Hooft L, van Munster BC, Stott DJ. Home or foster home care versus institutional long-term care for functionally dependent older people. Cochrane Database Syst Rev. 2017; 4:CD009844. https://doi.org/10.1002/14651858.CD009844.pub2.

24. Gandek B, Ware JE, Aaronson NK, Apolone G, Bjorner JB, Brazier JE, et al. Cross validation of item selection and scoring for the SF-12 health survey in nine countries: results from the IQOLA project. International quality of life assessment. J Clin Epidemiol. 1998;51:1171-8. https://doi.org/10.1016/S08954356(98)00109-7.

25. Mahoney FI, Barthel DW. Functional evaluation: The Barthel Index. Md State Med J 1965;14-61-5.

26. Lawton MP, Brody EM. Assessment of older people: self-maintaining and instrumental actvities of daily living. Gerontologist. 1969;9:179-86.

27. Podsiadlo D, Richardson S. The timed "up \& go": a test of basic functional mobility for frail elderly persons. J Am Geriatr Soc. 1991;39(2):142-8. https:// doi.org/10.1111/j.1532-5415.1991.tb01616.x. 
28. Lobo A, Saz P, Marcos G, Día JL, de la Cámara C, Ventura T, et al. Revalidación y normalización del miniexamen cognoscitivo (primera versión en castellano del Minimental State Examination) en la población general geriátrica. Med Clin (Barc). 1999;112:767-74.

29. Folstein MF, Folstein SE, McHugh PR. "mini-mental state". A practical method for grading the cognitive state of patients for the clinician. J Psychiatr Res. 1975;12:189-98. https://doi.org/10.1016/0022-3956(75)90026-6.

30. Sheikh JL, Yesavage JA. Geriatric Depression Scales (GDS): Recent evidence and development of a shorter version. Brink TL, editors. Clinical Gerontology: A guide to assessment and intervention. New York: Haworth Press. 1986, p. 165

31. Kaiser MJ, Bauer JM, Ramsch C, Uter W, Guigoz Y, Cederholm T, et al. Validation of the mini nutritional assessment short-form (MNA ${ }^{\oplus}$-SF): a practical tool for identification of nutritional status. J Nutr Health Aging. 2009;13:782-8. https://doi.org/10.1007/s12603-009-0214-7.

32. Jaeger E. Über Staar und Staaroperationen nebst anderer Beobachtungen und Erfahrungen. Seidel und Sohn: Wien; 1854.

33. Lichtenstein MJ, Bess FH, Logan SA. Validation of screening tools for identifying hearing-impaired elderly in primary care. JAMA. 1988;259(19): 2875. https://doi.org/10.1001/jama.1988.03720190043029.

34. Avery K, Donovan J, Peters TJ, Shaw C, Gotoh M, Abrams P. ICIQ: a brief and robust measure for evaluating the symptoms and impact of urinary incontinence. Neurourol Urodyn. 2004;23:322-30. https://doi.org/10.1002/nau.20041.

35. Fried LP, Bandeen-Roche K, Kasper JD, Guralnik JM. Association of comorbidity with disability in older women: the Women's health and aging study. J Clin Epidemiol. 1999;52(1):27-37. https://doi.org/10.1016/s08954356(98)00124-3.

36. Valderrama-Gama E, Damián J, Ruigómez A, Martín-Moreno JM. Chronic disease, functional status, and self-ascribed causes of disabilities among noninstitutionalized older people in Spain. J Gerontol A Biol Sci Med Sci. 2002;57(11):M716-21. https://doi.org/10.1093/gerona/57.11.m716.

37. García González JV, Díaz Palacios E, Salamea García A, et al. Evaluación de la fiabilidad y validez de una escala de valoración social en el anciano. Aten Primaria. 1999;23(7):434-40.

38. Fine JP, Gray RJ. A proportional hazards model for the subdistribution of a competing risk. JASA. 1999;94:496-509. https://doi.org/10.1080/01621459. 1999.10474144.

39. Pencina MJ, D'agostino RB. Overall $C$ as a measure of discrimination in survival analysis: model specific population value and confidence interval estimation. Stat Med. 2004;23:2109-23. https://doi.org/10.1002/sim.1802.

40. Gerds TA. Prediction Error Curves for Risk Prediction Models in Survival Analysis. Package "pec". Version 2018.07.26. Available from: https://cran.rproject.org/web/packages/pec/pec.pdf. Accessed 7 July 2020.

41. Xiang $X_{1}$ Chen J, Kim M. Trajectories of Homebound Status in Medicare Beneficiaries Aged 65 and Older. Gerontologist. 2019. pii: gnz023. doi: https://doi.org/10.1093/geront/gnz023.

42. Wolff JL, Mulcahy J, Roth DL, Cenzer IS, Kasper JD, Huang J, et al. Long-term nursing home entry: a prognostic model for older adults with a family or unpaid caregiver. J Am Geriatr Soc. 2018;66:1887-94. https://doi.org/10. 1111/jgs.15447.

43. Luppa M, Riedel-Heller SG, Luck T, Wiese B, Van den Bussche H, Haller F, et al. Age-related predictors of institutionalization: results of the German study on ageing, cognition and dementia in primary care patients (AgeCoDe). Soc Psychiatry Psychiatr Epidemiol. 2012;47(2):263-70. https:// doi.org/10.1007/s00127-010-0333-9.

44. AGE Platform Europe. Older people also suffer because of the crisis. 2012. Brussels. Available from: https://www.age-platform.eu/publications/olderpeople-also-suffer-because-crisis. Accessed 7 July 2020.

45. Rodrigues $\mathrm{R}$, llinca $\mathrm{S}$, Schmidt A. Analysing equity in the use of long-term care in Europe. Research note 9/2014. European Centre for Social Welfare Policy and Research. Brussels. 2014. Available from: https://ec.europa.eu/ social/BlobServlet?docld=13627\&langld=en. Accessed 7 July 2020.

46. Instituto Nacional de Estadística. Tablas de mortalidad, año 2017. INE. 2018 Available from: http://www.ine.es/dyngs/INEbase/es/operacion.htm?c= Estadistica_C\&cid=1254736177004\&menu=ultiDatos\&idp=1254735573002. Accessed 7 July 2020.

47. Ourhashémi F, Andrieu S, Gillette-Guyonnet S, Vellas B, Albarède JL, Grandjean $\mathrm{H}$. Instrumental activities of daily living as a potential marker of frailty: a study of 7364 community-dwelling elderly women (the EPIDOS study). J Gerontol A Biol Sci Med Sci. 2001;56(7):M448-53. https://doi.org/10. 1093/gerona/56.7.m448.
48. Schuurmans H, Steverink N, Lindenberg S, Frieswijk N, Slaets JP. Old or frail: what tells us more? J Gerontol A Biol Sci Med Sci. 2004;59(9):M962-5. https://doi.org/10.1093/gerona/59.9.m962.

49. Abellan van Kan G, Rolland Y, Bergman H, Morley JE, Kritchevsky SB, Vellas B. The I.A.N.A Task Force on frailty assessment of older people in clinical practice. J Nutr Health Aging. 2008;12(1):29-37. https://doi.org/10.1007/ BF02982161.

50. Savva GM, Donoghue OA, Horgan F, O'Regan C, Cronin H, Kenny RA. Using timed up-and-go to identify frail members of the older population. J Gerontol A Biol Sci Med Sci. 2013;68:441-6. https://doi.org/10.1093/gerona/ gls190.

51. Saum KU, Schöttker B, Meid AD, Holleczek B, Haefeli WE, Hauer K, Brenner H. Is Polypharmacy associated with frailty in older people? Results from the ESTHER cohort study. J Am Geriatr Soc. 2017;65(2):e27-32. https://doi.org/ 10.1111/jgs.14718.

52. Dhalwani NN, Fahami R, Sathanapally H, Seidu S, Davies MJ, Khunti K. Association between polypharmacy and falls in older adults: a longitudinal study from England. BMJ Open. 2017;7(10):e016358. https://doi.org/10.1136/ bmjopen-2017-016358.

53. Bonaga B, Sánchez-Jurado PM, Martínez-Reig M, Ariza G, Rodríguez-Mañas L, Gnjidic D, et al. Frailty, Polypharmacy, and health outcomes in older adults: the frailty and dependence in Albacete study. J Am Med Dir Assoc. 2018; 19(1):46-52. https://doi.org/10.1016/j.jamda.2017.07.008.

54. Midão L, Giardini A, Menditto E, Kardas P, Costa E. Polypharmacy prevalence among older adults based on the survey of health, ageing and retirement in Europe. Arch Gerontol Geriatr. 2018;78:213-20. https://doi.org/10.1016/j. archger.2018.06.018.

55. Freund J, Meiman J, Kraus C. Using electronic medical record data to characterize the level of medication use by age-groups in a network of primary care clinics. J Prim Care Community Health. 2013:4(4):286-93. https://doi.org/10.1177/2150131913495243.

56. Fried TR, O'Leary J, Towle V, Goldstein MK, Trentalange M, Martin DK. Health outcomes associated with polypharmacy in community-dwelling older adults: a systematic review. J Am Geriatr Soc. 2014;62(12):2261-72. https:// doi.org/10.1111/jgs.13153.

57. Morley JE, Vellas B, van Kan GA, Anker SD, Bauer JM, Bernabei R, et al. Frailty consensus: a call to action. J Am Med Dir Assoc. 2013;14(6):392-7. https:// doi.org/10.1016/j.jamda.2013.03.022.

58. Kaufmann CP, Tremp R, Hersberger KE, Lampert ML. Inappropriate prescribing: a systematic overview of published assessment tools. Eur J Clin Pharmacol. 2014;70(1):1-11. https://doi.org/10.1007/s00228-013-1575-8.

59. Steinbach U. Social networks, institutionalization, and mortality among elderly people in the United States. J Gerontol. 1992;47(4):S183-90. https:// doi.org/10.1093/geronj/47.4.s183.

60. Takeuchi M, Showa S, Kitazawa K, Mori M. Living alone is associated with an increased risk of institutionalization in older men: a follow-up study in Hamanaka town of Hokkaido, Japan. Geriatr Gerontol Int. 2018;18(6):867-72. https://doi.org/10.1111/ggi.13267.

61. Hajek A, Brettschneider C, Lange C, Posselt T, Wiese B, Steinmann S, et al. AgeCoDe Study Group. Longitudinal Predictors of institutionalization in Old Age. PLoS One. 2015;10(12):e0144203. https://doi.org/10.1371/journal.pone.0144203.

62. Pimouguet $C$, Rizzuto D, Schön P, Shakersain B, Angleman S, Lagergren M, et al. Impact of living alone on institutionalization and mortality: a population-based longitudinal study. Eur J Pub Health. 2016;26(1):182-7. https://doi.org/10.1093/eurpub/ckv052.

63. Lesende M. Crisis económica y vulnerabilidad social en personas mayores. Aten Primaria. 2014;46(2):55-7. https://doi.org/10.1016/j.aprim.2013.11.001.

64. O'Caoimh R, Cornally N, Svendrovski A, Weathers E, FitzGerald C, Healy E, et al. Measuring the Effect of Carers on Patients' Risk of Adverse Healthcare Outcomes Using the Caregiver Network Score. J Frailty Aging. 2016;5(2): 104-10. doi: https://doi.org/10.14283/jfa.2016.86.

65. Makizako H, Shimada H, Doi T, Tsutsumimoto K, Hotta R, Nakakubo S, et al. Social Frailty Leads to the Development of Physical Frailty among Physically Non-Frail Adults: A Four-Year Follow-Up Longitudinal Cohort Study. Int J Environ Res Public Health. 2018;15(3). pii: E490. doi: https://doi.org/10.3390/ijerph15030490.

66. Bunt S, Steverink N, Olthof J, van der Schans CP, Hobbelen JSM. Social frailty in older adults: a scoping review. Eur J Ageing. 2017;14(3):323-34. https:// doi.org/10.1007/s10433-017-0414-7.

67. Luppa M, Luck T, Weyerer S, König HH, Riedel-Heller SG. Gender differences in predictors of nursing home placement in the elderly: a systematic review. 
Int Psychogeriatr. 2009;21(6):1015-25. https://doi.org/10.1017/ S1041610209990238.

68. Romera-Liebana L, Orfila F, Segura JM, Real J, Fabra ML, Möller M, et al. Effects of a primary care-based multifactorial intervention on physical and cognitive function in frail, elderly individuals: a randomized controlled trial. J Gerontol A Biol Sci Med Sci. 2018;73(12):1688-74. https://doi.org/10.1093/ gerona/gl $\times 259$

69. Inzitari M, Pérez LM, Enfedaque MB, Soto L, Díaz F, Gual N, et al. Integrated primary and geriatric care for frail older adults in the community: implementation of a complex intervention into real life. Eur J Intern Med. 2018;56:57-63. https://doi.org/10.1016/j.ejim.2018.07.022.

70. Gené L, Navarro M, Kostov B, Ortega M, Colungo C, Carpallo M, et al. Pre frail 80: multifactorial intervention to prevent progression of pre-frailty to frailty in the elderly. J Nutr Health Aging. 2018;22(10):1266-74. https://doi. org/10.1007/s12603-018-1089-2.

\section{Publisher's Note}

Springer Nature remains neutral with regard to jurisdictional claims in published maps and institutional affiliations.

Ready to submit your research? Choose BMC and benefit from:

- fast, convenient online submission

- thorough peer review by experienced researchers in your field

- rapid publication on acceptance

- support for research data, including large and complex data types

- gold Open Access which fosters wider collaboration and increased citations

- maximum visibility for your research: over $100 \mathrm{M}$ website views per year

At BMC, research is always in progress.

Learn more biomedcentral.com/submissions 